\title{
ANÁLISE DA PERDA PRIMÁRIA DE IMPLANTES DENTÁRIOS REALIZADOS NA ÁREA DE CIRURGIA BUCO-MAXILO-FACIAL DA FACULDADE DE ODONTOLOGIA DE PIRACICABA- UNICAMP.
}

\section{Graciele Dib Nunes Silva*, Cláudio Ferreira Nóia.}

\section{Resumo}

Falhas na terapia com Implantes Dentários podem ser atribuídas a uma série de fatores, sendo a quantidade e qualidade óssea um dos mais relevantes. Essas falhas podem ocorrer antes da reabilitação protética do Implante, sendo chamadas de falhas primárias, ou após a reabilitação protética do mesmo, sendo chamadas de falhas tardias. Sendo assim, o objetivo do presente trabalho foi analisar retrospectivamente a perda primária de Implantes Dentários realizados na Área de Cirurgia Buco-Maxilo-Facial da Faculdade de Odontologia de Piracicaba da Universidade Estadual de Campinas (FOP-UNICAMP). Para isso, foram analisadas as seguintes variáveis: gênero, tabagismo, enxertia óssea prévia, tipo de implante, região anatômica, região nos maxilares, além do diâmetro e comprimento dos implantes.

\section{Palavras-chave:}

Implante dentário, Osseointegração, Perda primária.

\section{Introdução}

Neste estudo avaliou-se a perda primária de implantes dentários instalados na Faculdade de Odontologia de Piracicaba, no período de Janeiro de 1996 a Dezembro de 2017.

\section{Resultados e Discussão}

Foram consideradas as seguintes variáveis: gênero, tabagismo, enxertia óssea prévia, tipo de implante, região anatômica, atém do diâmetro e comprimento dos implantes. Para estabelecer comparações entre os pacientes que tiveram implantes perdidos daqueles que não tiveram perda foi utilizado o teste qui-quadrado, sendo considerado resultado estatisticamente significativo para valores de $p<0,05$.

Resultados estatisticamente significativos: Pacientes tabagistas tiveram maior perda em relação aos não tabagistas. A região posterior apresentou maior perda em relação a anterior. Os implantes SD (estreitos) e WD (largos) tiveram maior perda em relação aos RD (regular) quando comparados separadamente.

Tabela 1 - Avaliação da perda precoce de implantes em relação a características da amostra

\begin{tabular}{lcccc}
$\begin{array}{l}\text { Variáveis } \\
\text { analisadas }\end{array}$ & \multicolumn{4}{c}{$\begin{array}{l}\text { Implante } \\
\text { perdido }(\mathbf{n})\end{array}$} \\
\hline \multirow{2}{*}{ Gênero } & Não & Sim & p \\
& F & 620 & 15 & 0,497 \\
Tabagismo & N & 345 & 6 & \\
& S & 898 & 11 & $<0,01$ \\
& S & 180 & 10 &
\end{tabular}

\begin{tabular}{lcccc} 
Enxertia óssea & $\mathrm{S}$ & 951 & 18 & 0,725 \\
prévia & $\mathrm{N}$ & 127 & 3 & \\
Tipo de & $\mathrm{HE}$ & 938 & 20 & 0,05 \\
Implante & $\mathrm{HI}$ & 86 & 3 & \\
& $\mathrm{CM}$ & 50 & 5 & \\
Região & Maxila & 524 & 11 & 0,735 \\
anatômica & Mandíbula & 553 & 10 & \\
Região nos & Anterior & 518 & 4 & $<0,01$ \\
maxilares & Posterior & 559 & 17 & \\
Diâmetro do & SD & 123 & 5 & $<0,01$ \\
implante & RD & 783 & 7 & \\
& WD & 172 & 9 & \\
Comprimento & Extra-curto & 37 & 2 & 0,06 \\
do implante & Curto & 89 & 5 & \\
& Médio & 891 & 14 & \\
& Longo & 41 & 0 & \\
\hline
\end{tabular}

\section{Conclusões}

Apesar de ser baixo, o índice de perda primária de implantes dentários mostrou-se relacionado com fatores como o hábito de fumar, a região de instalação do mesmo no osso, bem como com o diâmetro do implante.

\footnotetext{
1 Ellis, E.R.; Tucker, M.R.; Hupp, J.R.; Cirurgia Oral e Maxilofacia Contemporânea - Rio de Janeiro: Elsevier. 2009; 5(4): 213-61

2 Mazzonetto R.; Duque Neto H.; Nascimento F.F.; Enxertos Ósseos em Implantodontia. Editora Napoleão. 2012; 1(1)

3 Tolstunov L. Implant zones of the jaws: implant location and related success rate. J Oral Implantol. 2007; 33(4): 211-20.
} 